\title{
EVALUATION OF CORRELATION OF SERUM PROGESTERONE LEVEL WITH PREGNANCY OCCURRENCE IN FROZEN EMBRYO TRANSFER
}

\author{
Leila Zarei1, Tahereh Behroozilak², Masoumeh Hajshafiyiha ${ }^{3}$, Roya Azizzadeh4, Aelham Talebi ${ }^{5}$, Shiba Abdollah ${ }^{6}$, Ahmad Hajebrahimi $^{7}$
}

${ }_{1}^{1}$ Department of Anatomical Science, Faculty of Medicine, Lorestan University of Medical Sciences, Khorramabad, Iran.

${ }^{2}$ Reproductive Health Research Center, Department of Obstetrics and Gynaecology, Urmia University of Medical Sciences, Urmia, Iran. ${ }^{3}$ Reproductive Health Research Center, Department of Obstetrics and Gynaecology, Urmia University of Medical Sciences, Urmia, Iran. ${ }^{4}$ Reproductive Health Research Center, Department of Obstetrics and Gynaecology, Urmia University of Medical Sciences, Urmia, Iran. ${ }^{5}$ Reproductive Health Research Center, Department of Obstetrics and Gynaecology, Urmia University of Medical Sciences, Urmia, Iran. ${ }^{6}$ Student of Research Committee, Urmia University of Medical Sciences, Urmia, Iran.

${ }^{7}$ Reproductive Health Research Center, Department of Obstetrics and Gynaecology, Urmia University of Medical Sciences, Urmia, Iran. ABSTRACT

\section{BACKGROUND}

Progesterone is an endogenous hormone secreted by ovaries that prepares uterine endometrium for implantation. The aim of this study was to evaluate the relation of serum progesterone level on the day of transferring frozen embryo with pregnancy occurrence.

\section{MATERIALS AND METHODS}

161 women were chosen for frozen embryo transfer. From the second day of their cycle, they were treated with $2 \mathrm{mg}$ per 8 hours estradiol. From the 13th day, $5 \mathrm{mg}$ intramuscular (IM) progesterone was injected every 12 hours to increase endometrium thickness above $8 \mathrm{~mm} .4$ days after progesterone administration, embryo transfer was performed, and progesterone level was measured. Pregnancy occurrence was also evaluated.

\section{RESULTS}

The average progesterone level in 25 women with positive beta HCG was $26.26 \pm 8.58$ on $1^{\text {st }}$ day, $26.63 \pm 8.22$ on $17^{\text {th }}$ day and $24.3 \pm 11.48$ on the $18^{\text {th }}$ day of transfer. In 136 non-pregnant women it was $25.61 \pm 16.01$ on $1^{\text {st }}$ day, $29.03 \pm 14.45$ on $17^{\text {th }}$ day and $15.42 \pm 2.77$ on $18^{\text {th }}$ day.

\section{CONCLUSION}

There was no relationship between serum level of progesterone on the day of transfer and pregnancy occurrence.

\section{KEY WORDS}

Frozen Embryo Transfer, Progesterone, Pregnancy.

HOW TO CITE THIS ARTICLE: Zarei L, Behroozilak T, Hajshafiyiha M, et al. Evaluation of correlation of serum progesterone level with pregnancy occurrence in frozen embryo transfer. J. Evolution Med. Dent. Sci. 2018;7(38):4245-4248, DOI: $10.14260 /$ jemds/2018/947

\section{BACKGROUND}

Infertility is defined as the failure to engender after one year of unprotected proximity in women less than 35 years of age and after 6 months in women over 35 years of age.(1) Epidemiological data indicated that about $10-15 \%$ of couples are suffering from infertility.(2) Management includes fertility counselling, lifestyle modifications, medical/ surgical treatment of underlying conditions, fertility medications, Assisted Reproductive Technologies (ARTs), serving as Intrauterine Insemination (IUI) and In Vitro Fertilisation (IVF)/ Intracytoplasmic Sperm Injection (ICSI).(3) The harmonic differentiation of embryo to blastocyst and uterine preparation for admission of blastocyst are essential factors defining women's fertility.(4) Distraction in transferred embryo implantation is one of the most important issues in the failure of ART method.(5)

'Financial or Other Competing Interest': None.

Submission 11-08-2018, Peer Review 03-09-2018,

Acceptance 10-09-2018, Published 17-09-2018.

Corresponding Author:

Tahereh Behroozilak,

Reproductive Health Research Center,

Department of Obstetrics and Gynaecology,

Urmia University of Medical Sciences, Urmia, Iran.

E-mail: t.behrooz2@yahoo.com

DOI: $10.14260 /$ jemds $/ 2018 / 947$
There are two methods of embryo transfer in IVF: frozen embryo transfer and fresh embryo transfer. Frozen embryo transfer increases cumulative pregnancy ratio and decreases costs, is easy to perform and could be administered successfully in a relatively shorter time span compared with repeated fresh cycles.(6) Frozen embryo transfer is done in two manners: slow and very fast. Compared with the traditional slow freezing method, the very fast method (embryo vitrification) that is introduced recently includes an ultrafast cryopreservation that inhibits ice formation within the suspension which is transformed to a glass-like solid, avoiding damage to the cells or tissues.(7) In the ovaries, progesterone is synthesized in the mitochondria of granulosa cells from cholesterol.(8) Progesterone is an endogenous hormone secreted by ovaries that prepares the endometrium of uterine by delivering nutrients to the foetus. It also suppresses uterine contractility by attaching to its receptors. $(9,10)$ Although, some studies rejected the relationship between progesterone and pregnancy ratio, ${ }^{(11,12)}$ others reported an inverse relationship. $(13,14)$

In this study, we evaluated the rate of implantation and abortion in patients whose embryos were frozen due to complications such as inappropriate thickness of the endometrium, uterine bleeding etc. Frozen embryos were subsequently transferred to prepared endometrium and the effect of progesterone in foetal implantation in the uterine 
cavity was investigated. According to the serum progesterone level in the examined cycles and to prevent unsuccessful occurrence of pregnancy, we transferred immediately to postpone the transfer of frozen embryo.

\section{MATERIALS AND METHODS}

\section{Study Design}

Patients referring to IVF center of Urmia Kosar Hospital between May 2013 and December 2015, being candidates for IVF were evaluated in this prospective observational study. We got an approval from the Ethical Committee of Urmia University of Medical Sciences and informed consent from all participants. Totally, 161 patients received ICSI-ET treatment. The study was designed to determine the pregnancy outcomes and abortion according to progesterone serum level on the day of transfer.

\section{Study Population}

Inclusion criteria involved patients who were candidates for IVF, but after oocyte retrieval their embryos were frozen due to complications such as ovarian hyperstimulation syndrome, uterine bleeding, inappropriate thickness of endometrium, polyp, any space occupying mass in uterus and cervical stenosis. Totally, 200 patients met inclusion criteria. Exclusion criteria included smokers, patients with systemic diseases and those who had received hormone therapy. So 39 people were excluded from exclusion list. A total of 161 women with ICSI-ET (Intracytoplasmic Sperm Injection followed by Embryo Transfer) treatment were evaluated.

\section{Treatment Protocol}

Patients were applied for endometrial preparation from the first or second day of their period cycle after oocyte retrieval via ultrasound-guided transvaginal aspiration. They were treated with estradiol at a dose of $2 \mathrm{mg}$ per 8 hours. On the $13^{\text {th }}$ or $14^{\text {th }}$ day of the cycle, endometrium thickness was examined. In the cases where endometrium thickness was more than $8 \mathrm{~mm}, 50 \mathrm{mg}$ of intramuscular (IM) progesterone were injected each 12 hours and estradiol treatment was continued. On the $4^{\text {th }}$ day of progesterone administration, blood was drawn for each patient prior to the embryo transfer. Embryo transfer was performed, but progesterone and estradiol injections were continued. After 14 - 15 days, BHCG level was checked. In the cases where the results were positive, they were referred to ultrasound center. When gestational sac in uterus along with foetal cardiac activity were observed, the case was considered as positive pregnancy. For surveillance of miscarriage, all patients were followed up for about 14 weeks of gestation. Embryos were graded according to their morphologies and cleavage rate. $122(75.8 \%)$ embryos were transferred on $17^{\text {th }}$ day and 39 (24.2\%) of them on $18^{\text {th }}$ day.

\section{Sampling}

Blood samples were obtained for progesterone measurement from the day of embryo transfer. $2.5 \mathrm{~mL}$ of venous blood samples were collected from the patients and sent to clinical laboratory of the hospital to measure the serum progesterone level. All isolated serum samples were kept frozen at $-18^{\circ} \mathrm{c}$. The serum samples were melt at room temperature and progesterone levels on the day of transferring frozen embryo were measured by luminescence assay using traditional kits (LIAISON, DiaSorin, USA).

\section{Statistical Analysis}

Data analysis was performed by student's t-test using Statistical Packages of Social Sciences (SPSS) version 20 (IBM, Chicago, IL). Results were reported as mean \pm SD, and percentages for outcomes of the patients were calculated. We considered a $\mathrm{P}$ value of $<0.05$ as statistically significant.

\section{RESULTS}

Basic characteristics and Assisted Reproductive Technique (ART) parameters are shown in Table 1. The overall ongoing pregnancy and miscarriage ratio are shown in Table 2 . An average progesterone level in 25 women with positive BHCG was $26.26 \pm 8.58$ and in 136 non-pregnant women was $25.61 \pm 16.01(\mathrm{P}$ value $=0.84)$. There was no significant relationship between serum progesterone levels with pregnancy rates. In this study, we compared the average level of progesterone according to embryo transfer day (Table 3).

There was no significant difference in serum progesterone level of women with positive BHCG in comparison with non-pregnant women according to embryo transfer day. As seen in Table 4, A-B grade in 26 cases $(16.1 \%)$ and grade $\mathrm{A}$ in 23 cases $(14.3 \%)$ were the most prevalent grading of transferred embryos. There was no significant difference observed in serum progesterone level and pregnancy occurrence $(p>0.05$, Table 5$)$.

\begin{tabular}{|c|c|}
\hline Variable & Mean \pm SD \\
\hline Age (years) & $30.82 \pm 5.41$ \\
\hline Number of embryos transferred & $2.63 \pm 0.93$ \\
\hline $\begin{array}{c}\text { Progesterone on transfer day } \\
(\mathrm{ng} / \mathrm{mL})\end{array}$ & $15.08 \pm 25.71$ \\
\hline Basal FSH (mIU/mL) & $2.13 \pm 6.57$ \\
\hline \multicolumn{2}{|c|}{ FSH: Follicle-Stimulating Hormone } \\
\hline
\end{tabular}

\begin{tabular}{|c|c|c|}
\hline Variable & Positive & Negative \\
\hline $\begin{array}{c}\text { Clinical pregnancy } \\
\text { rate }\end{array}$ & $25(15.5 \%)$ & $136(84.5 \%)$ \\
\hline Early abortion & $5(3.1 \%)$ & $156(96.9 \%)$ \\
\hline \multicolumn{2}{|c|}{ Table 2. Pregnancy and Miscarriage Rate } \\
\hline
\end{tabular}

\begin{tabular}{|c|c|c|c|}
\hline \multirow{2}{*}{ Variable } & \multicolumn{2}{|c|}{ BHCG } & \\
\cline { 2 - 4 } & Positive & Negative & P value \\
\hline $\begin{array}{c}\text { Serum P level of } \\
\text { mothers with } \\
\text { transferred embryo on } \\
\text { the 17th day }\end{array}$ & $26.63 \pm 8.22$ & $29.03 \pm 14.45$ & 0.46 \\
\hline $\begin{array}{c}\text { Serum P level of } \\
\text { mothers with } \\
\text { transferred embryo on } \\
\text { the 18th day }\end{array}$ & $24.30 \pm 11.48$ & $15.42 \pm 2.77$ & 0.31 \\
\hline \multicolumn{2}{|c|}{ P= Progesterone (ng/mL) } \\
\hline $\begin{array}{c}\text { Table 3. Comparison of Serum Progesterone Level due to } \\
\text { Embryo Transfer Time }\end{array}$ \\
\hline
\end{tabular}




\begin{tabular}{|c|c|c|}
\hline Grading & Frequency & Percent \\
\hline $\mathrm{a}-\mathrm{b}$ & 26 & 16.1 \\
\hline $\mathrm{a}$ & 23 & 14.3 \\
\hline $\mathrm{b}$ & 20 & 12.4 \\
\hline $\mathrm{a} 2-\mathrm{b}$ & 15 & 9.3 \\
\hline $\mathrm{b}-\mathrm{c}$ & 13 & 8.1 \\
\hline $\mathrm{a}-\mathrm{b}-\mathrm{c}$ & 10 & 6.2 \\
\hline $\mathrm{a}-\mathrm{b}-\mathrm{c} 2$ & 1 & 0.6 \\
\hline $\mathrm{a}-\mathrm{b} 2$ & 1 & 0.6 \\
\hline $\mathrm{a}-\mathrm{c}$ & 4 & 2.5 \\
\hline $\mathrm{a} 1-\mathrm{b} 2$ & 6 & 3.7 \\
\hline $\mathrm{a} 1-\mathrm{b} 2-\mathrm{c} 1$ & 4 & 2.5 \\
\hline $\mathrm{a} 2$ & 2 & 1.2 \\
\hline $\mathrm{a} 2-\mathrm{b} 2$ & 6 & 3.7 \\
\hline $\mathrm{a} 2-\mathrm{b} 2-\mathrm{c}$ & 1 & 0.6 \\
\hline $\mathrm{a} 3$ & 2 & 1.2 \\
\hline $\mathrm{a} 4-\mathrm{b}$ & 1 & 0.6 \\
\hline $\mathrm{B}-\mathrm{c} 2$ & 7 & 4.3 \\
\hline $\mathrm{B} 1-\mathrm{c} 4$ & 1 & 0.6 \\
\hline $\mathrm{B} 2-\mathrm{c}$ & 8 & 5 \\
\hline B2-c2 & 8 & 5 \\
\hline B2-c3 & 1 & 0.6 \\
\hline C2-b3 & 1 & 0.6 \\
\hline Total & $\mathbf{1 6 1}$ & $\mathbf{1 0 0}$ \\
\hline Table 4. Distribution of Pregnancy and Percentage of \\
& Embryo's Grading \\
\hline \multicolumn{2}{|c|}{} & \\
\hline
\end{tabular}

\begin{tabular}{|c|c|c|c|}
\hline \multirow{2}{*}{ Variable } & \multicolumn{2}{|c|}{ BHCG } & \multirow{2}{*}{ P value } \\
\cline { 2 - 3 } & Negative & Positive & \\
\hline $\begin{array}{c}\text { Serum } \\
\text { progesterone } \\
\text { level at the day } \\
\text { of transfer }\end{array}$ & $25.61 \pm 16.01$ & $26.26 \pm 8.58$ & 0.84 \\
\hline Table 5. Comparison of Serum Progesterone Level due to \\
occurrence of Pregnancy \\
\hline
\end{tabular}

\section{DISCUSSION}

The number of women accomplishing frozen embryo transfer has been increased in this decade, that has many reasons including elective and medically indicated oocyte and embryo conservation. There are three different routes of exogenous progesterone treatment: vaginal, intramuscular and oral.(13,14) Comparing to human chorionic gonadotropin (BHCG), the use of progesterone level has better FET cycles performance support and is superior to the use of BHCG.(15) Progesterone results in a lower chance of ovarian hyperstimulation syndrome.(13) So it is necessary to understand the impact of progesterone support and optimal progesterone values during FET. Progesterone prepares uterine endometrium for implantation and delivers nutrient substances to the foetus by stimulation of endometrial glands. It also suppresses uterine contractions. $(9,10)$ The impact of progesterone rise on IVF outcomes has been the subject of many studies.(11,16,17) Some studies rejected the relationship between progesterone and pregnancy rates,(11,12) while others reported an inverse association. $(13,14)$ The early studies reported no relationship between pre-ovulatory progesterone rise and pregnancy rates.(11,16,17) In most related studies, high serum progesterone level prevents the increase in pregnancy rate and likelihood of live birth. Although, progesterone levels on the day of transfer have not yet been investigated extensively in humans, planning the exact time of frozen embryo transfer based on progesterone values alone concludes with higher pregnancy rates.(18)
The aim of this cross-sectional study was to evaluate the rate of implantation and abortion in patients whose embryo has been frozen due to reasons such as inappropriate endometrial thickness, uterine bleeding etc. and their embryos have been subsequently transferred followed by preparing the endometrium. In this study, we evaluated the effect of progesterone on embryo implantation in the uterus. The results of this study was contradicted with the study of Nawroth F (2015), which deduced that pregnancy rates have decreased with the increase of serum progesterone level in pregnants.(19) Although, there was no significant difference in our study, serum progesterone levels were in pregnant women.

In a study done by Kofinas JD et al in 2015, the increase in serum progesterone level resulted in a reduction in the incidence of pregnancy to live birth. They concluded that serum progesterone levels above $20 \mathrm{ng} / \mathrm{mL}$ on the day of transfer decreases the rate of pregnancy of live births.(20) These results are completely different with our findings. Because in our study we have just investigated the occurrence of pregnancy and live births were not among our goals of study and so have not been studied. However, they need to be studied in future studies.

Considering the fact that in most of the studies, the embryo transfer day was effective in pregnancy, we evaluated the occurrence of pregnancy according to embryo transfer day with serum progesterone levels. $75.8 \%$ of embryos were transmitted on $17^{\text {th }}$ day and $24.2 \%$ on $18^{\text {th }}$ day and the results showed that mean serum progesterone level on the day of transfer in 25 women with positive BHCG was $26.26 \pm 8.22$ on $17^{\text {th }}$ day and $24.3 \pm 11.48$ on $18^{\text {th }}$ day of period cycle and in 136 non-pregnant women it was $29.03 \pm 14.45$ on $17^{\text {th }}$ day and $15.42 \pm 2.77$ on $18^{\text {th }}$ day of the period cycle. There was no statistically significant difference in progesterone levels in women regarding pregnancy incidence. These findings also showed that there is a controversial effect of serum progesterone on pregnancy occurrence.

\section{CONCLUSION}

Our findings showed that there was no association between serum progesterone level on the day of transfer and pregnancy occurrence.

\section{REFERENCES}

[1] Weiss RV, Clapauch R. Female infertility of endocrine origin. Arquivos Brasileiros de Endocrinologia \& Metabologia 2014;58(2):144-52.

[2] Mascarenhas MN, Flaxman SR, Boerma T, et al. National, regional and global trends in infertility prevalence since 1990: a systematic analysis of 277 health surveys. PLoS medicine 2012;9(12):e1001356.

[3] Nardelli AA, Stafinski T, Motan T, et al. Assisted reproductive technologies (ARTs): evaluation of evidence to support public policy development. Reproductive Health 2014;11(1):76.

[4] Ma WG, Song H, Das SK, et al. Estrogen is a critical determinant that specifies the duration of the window of uterine receptivity for implantation. Proceedings of the National Academy of Sciences 2003;100(5):29638. 
[5] Sharara FI, McClamrock HD. High estradiol levels and high oocyte yield are not detrimental to in vitro fertilization outcome. Fertility and Sterility 1999;72(3):401-5.

[6] Eftekhar M, Rahsepar M, Rahmani E. Effect of progesterone supplementation on natural frozenthawed embryo transfer cycles: a randomized controlled trial. International Journal of Fertility \& Sterility 2013;7(1):13-20.

[7] Li Z, Wang Y, Ledger W, et al. Clinical outcomes following cryopreservation of blastocysts by vitrification or slow freezing: a population-based cohort study. Human Reproduction 2014;29(12):2794-801.

[8] Fang L, Yu Y, Zhang R, et al. Amphiregulin mediates hCG-induced StAR expression and progesterone production in human granulosa cells. Scientific Reports 2016;6: Art. No. 24917.

[9] Coomarasamy A, Williams H, Truchanowicz E, et al. PROMISE: first-trimester progesterone therapy in women with a history of unexplained recurrent miscarriages-a randomised, double-blind, placebocontrolled, international multicentre trial and economic evaluation. Health Technology Assessment (Winchester, England) 2016;20(41):1-92.

[10] Nadeem L, Shynlova 0, Matysiak-Zablocki E, et al. Molecular evidence of functional progesterone withdrawal in human myometrium. Nature Communications 2016;7:11565.

[11] Martínez F, Coroleu B, Clua E, et al. Serum progesterone concentrations on the day of HCG administration cannot predict pregnancy in assisted reproduction cycles. Reproductive Biomedicine Online 2004;8(2):183-90.

[12] Andersen CY, Bungum L, Andersen AN, et al. Preovulatory progesterone concentration associates significantly to follicle number and LH concentration but not to pregnancy rate. Reproductive Biomedicine Online 2011;23(2):187-95.
[13] Penzias AS. Luteal phase support. Fertility and Sterility 2002;77(2):318-23.

[14] Shapiro DB, Pappadakis JA, Ellsworth NM, et al. Progesterone replacement with vaginal gel versus i.m. injection: cycle and pregnancy outcomes in IVF patients receiving vitrified blastocysts. Human Reproduction (Oxford, England) 2014;29(8):1706-11.

[15] Van der Linden M, Buckingham K, Farquhar C, et al. Luteal phase support for assisted reproduction cycles. Cochrane Database Syst Rev 2011;10(5): CD009154.

[16] Bustillo M, Stern JJ, Coulam CB. Serum progesterone at the time of human chorionic gonadotrophin does not predict pregnancy in in-vitro fertilization and embryo transfer. Human Reproduction 1995;10(11):2862-7.

[17] Edelstein MC, Seltman HJ, Cox BJ, et al. Progesterone levels on the day of human chorionic gonadotropin administration in cycles with gonadotropin-releasing hormone agonist suppression are not predictive of pregnancy outcome. Fertility and Sterility 1990;54(5):853-7.

[18] Dong Z, Sun L, Zhang H, et al. The frozen-thawed embryo transfer timing determined by serum progesterone level: a retrospective follow-up study. European Journal of Obstetrics and Gynecology and Reproductive Biology 2014;181:210-3.

[19] Nawroth F, Ludwig M. What is the 'ideal' duration of progesterone supplementation before the transfer of cryopreserved-thawed embryos in estrogen/progesterone replacement protocols? Human Reproduction 2005;20(5):1127-34.

[20] Kofinas JD, Blakemore J, McCulloh DH, et al. Serum progesterone levels greater than $20 \mathrm{ng} / \mathrm{dl}$ on day of embryo transfer are associated with lower live birth and higher pregnancy loss rates. Journal of Assisted Reproduction and Genetics 2015;32(9):1395-9. 